Kleber MORENO ${ }^{1}$

Ana Paula Frederico

Rodrigues Loureiro

BRACARENSE ${ }^{1}$

Correspondência para:

KleberMoreno

Departamento de Clínicas Veterinárias,

Centro de Ciências Agrárias, Universidade

Estadual de Londrina

Rod. Celso Garcia Cid, PR 445 km 380

Caixa Postal 6001 - Londrina -Pr, Cep

86051-990,kleber@uel.br

Recebido para publicação: 11/11/2005 Aprovado para publicação: 24/05/2007

\title{
Estudo retrospectivo de linfoma canino no período de 1990 - 2004 na região norte do Paraná
}

\author{
1 - Centro de Ciências Agrárias, Universidade Estadual de Londrina, \\ Londrina-PR
}

\section{Resumo}

O linfoma canino é a principal neoplasia de origem hemolinfática. Foram analisados 186 casos de linfoma diagnosticados entre 1990 a 2004. Observou-se que cães machos apresentaram uma ocorrência maior $(58,6 \%)$ do que em fêmeas (41,4\%). A idade média dos animais acometidos foi de 5,9 anos. As maiores ocorrências do linfoma foram observadas em cães sem raça definida (40,3\%), Pastor Alemão (8,6\%), Rottweiler (8,1\%) e Boxer (7,0\%). Quanto à classificação anatômica e estadiamento clínico, a maior ocorrência foi a da forma multicêntrica $(68,8 \%)$ e os estádios III $(37,1 \%)$ e IV $(43,5 \%)$, respectivamente.

\author{
Palavras-chaves: \\ Linfoma canino. \\ Epidemiologia. \\ Classificação anatômica. \\ Estadiamento clínico.
}

\section{Introdução}

O linfoma é uma neoplasia maligna com origem em tecido linfóide, sendo o principal tumor hematopoiético no cão. ${ }^{1} \mathrm{O}$ linfoma tem aparecimento espontâneo, representando de 8,5 a $9 \%$ de todos os tumores caninos. ${ }^{2}$ Caracteriza-se por elevada agressividade e, ao contrário do que ocorre em humanos, felinos, bovinos, roedores e aves, a relação com agentes virais não foi definitivamente demonstrada, apesar de relatos anteriores sobre a associação de retrovírus nas células tumorais. ${ }^{3}$ Fatores ambientais têm sido investigados na tentativa de determinar a etiologia do linfoma, principalmente quando da exposição ao herbicida 2,4 ácido diclorofenoxiacético (2,4 D). Estudo realizado em cães com linfoma expostos ao 2,4 D, através da técnica de reação em cadeia pela polimerase (PCR), demonstrou mutações no oncogene celular N-ras. ${ }^{4,5,6}$

Estudos epidemiológicos realizados em outros países, estimam incidência anual de aproximadamente 33 casos de linfoma para cada 100.000 cães. ${ }^{4} \mathrm{O}$ linfoma afeta cães de todas as idades, predominantemente os de meia idade (6,3 a 7,7 anos), não havendo predileção relacionada ao sexo. ${ }^{1,7} \mathrm{O}$ risco para o aparecimento do linfoma aumenta nas seguintes raças: Scottish Terrier; Basset Hound; Airedale Terrier; Bulldog; Boxer; Golden Retrievier, Poodle e Pastor Alemão., ${ }^{2,8}$ Raças de pequeno porte como Dachshund, Lulu da Pomerânia e Poodle miniatura têm menor risco ${ }^{10}$. Predisposição genética foi relatada em Bull Mastiff, um grupo de Otterhounds e uma família de Rottweilers. $^{6}$

O linfoma canino é classificado anatomicamente de acordo com a origem, seguindo a classificação anatômica proposta pela Organização Mundial de Saúde (OMS). ${ }^{11}$ Esta classificação contempla as seguintes categorias: multicêntrico, alimentar, mediastínico, cutâneo e extranodal, sendo a apresentação multicêntrica a mais comum, ocorrendo em até $84 \%$ dos casos.

Dentro da classificação anatômica proposta pela OMS, há o estadiamento clínico que compreende a extensão da doença em outros órgãos, presença de síndromes paraneoplásicas e sinais clínicos. ${ }^{12,13,14}$ Este estadiamento auxilia na determinação do prognóstico do animal com linfoma, variando o grau de I a V. A maioria dos animais apresenta-se com grau III ou IV da doença quando da avaliação clínica., ${ }^{1,10,15}$

O conhecimento destes dados tornase importante para estabelecer diagnóstico mais preciso e precoce, permitindo um 
tratamento adequado e uma melhora na taxa de sobrevida dos animais portadores de linfoma. Apesar de numerosos estudos sobre linfoma na literatura mundial, dados referentes a aspectos epidemiológicos são escassos no Brasil. O objetivo deste trabalho foi avaliar aspectos epidemiológicos do linfoma canino de casos encaminhados ao Hospital Veterinário da Universidade Estadual de Londrina (HV-UEL).

\section{Material e Método}

Foi realizado um levantamento de 186 casos de linfoma canino no Laboratório de Anatomia Patológica HV-UEL, no período de janeiro de 1990 a outubro de 2004. Os dados foram obtidos através dos prontuários de atendimento clínico e dos laudos de exames citológicos, histopatológicos ou de necropsias, de cães atendidos no HV-UEL e de material enviado por outras instituições do Estado, bem como de clínicas particulares da região Norte do Paraná.

Para todos os cães foram obtidos dados sobre idade, sexo e raça. Nos cães com linfoma foram obtidos dados da anamnese, do exame físico, porte físico, classificação anatômica e estadiamento clínico do tumor. A classificação anatômica e o estadiamento clínicos utilizados seguiram os critérios propostos pela Organização Mundial de Saúde. 7,11,16

Os cães foram classificados pelo porte físico em pequeno, médio, grande e gigante. Para os animais sem raça definida (SRD), o porte foi estabelecido pelo peso corpóreo sendo considerados de pequeno porte cães com peso $\leq$ a $10 \mathrm{~kg}$, porte médio $>10 \mathrm{e} \leq 20 \mathrm{~kg}$, grande porte $>20 \mathrm{e}$ $\leq 40 \mathrm{~kg}$ e cães gigantes com peso $>40 \mathrm{~kg}$.

Com intuito de se avaliar a influência da raça no aparecimento da doença, realizou-se um levantamento dos dados de todos os cães atendidos no HV-UEL $(\mathrm{n}=8560)$ no período entre outubro de 2002 a outubro de 2004, para determinar a distribuição das raças atendidas neste período. Desta forma pode verificar a existência de maior ocorrência da doença em raças com uma maior população hospitalar ou se realmente a influência racial contribui para o aparecimento da doença.

A análise estatística para avaliar a influência da raça na ocorrência do linfoma, foi realizado pelo teste de qui-quadrado, sendo considerado o nível de significância de 5\% $(\mathrm{p} \leq 0,05)$

\section{Resultados}

A distribuição racial dos cães foi heterogênea, sendo que 111 (59,7\%) eram de raça definida e 77 (40,3\%) SRD. Dentre os animais de raça definida, as raças que apresentaram maior ocorrência de linfoma foram Pastor Alemão, Rottweiler, Boxer e Cocker Spaniel Inglês (Tabela 1). Não houve diferença significativa na ocorrência de linfoma nas diferentes raças (Tabela 2).

Dos cães avaliados, 58,6\% (109/186) eram machos e 41,4\% (77/186) fêmeas. Ao analisar-se a freqüência de machos e fêmeas em relação as raças, verificou-se que este percentual sofre alterações de acordo com as raças (Tabela 1)

Quanto à faixa etária, observou-se maior ocorrência de linfoma em animais entre dois e cinco anos (84/186), seguido de cães com idade entre cinco e dez anos (78/186). Cães com menos de dois anos de idade ou acima de dez anos apresentaram uma ocorrência de 3,2\% (6/186) e 9,7\% (18/186), respectivamente.

Em cães com raça definida, observouse uma maior ocorrência em animais de grande porte $\left(37,9^{\circ} \%\right)$ e de raças gigantes $(31,5 \%)$. No entanto, em cães SRD houve uma inversão destas ocorrências, observando-se os maiores percentuais em cães de pequeno (44\%) e médio $(37,3 \%)$ porte (Figura 1).

Em relação à classificação anatômica, a apresentação multicêntrica foi a mais freqüente manifestando-se em $68,8 \%$ dos casos (Figura 2), seguido da apresentação cutânea $(12,9 \%)$.

Em relação ao estadiamento clínico da neoplasia, o estádio IV foi o mais freqüente com $43,5 \%$ dos casos, seguido do estádio III com 37,1\% (Figura 3). 
Tabela 1 - Distribuição do sexo de acordo com a raça, em 186 cães com linfoma atendidos no Laboratório de Anatomia Patológica do HV-UEL, no período de janeiro de 1990 a outubro de 2004. Londrina-Paraná -Brasil, 2005

\begin{tabular}{lccccc}
\hline \multicolumn{1}{c}{ Raças } & $\begin{array}{c}\text { Total de } \\
\text { animais }\end{array}$ & $\begin{array}{c}\text { \% de } \\
\text { fêmeas }\end{array}$ & $\begin{array}{c}\text { \% de } \\
\text { machos }\end{array}$ & $\begin{array}{c}\text { \% da raça no total } \\
\text { de animais com } \\
\text { linfoma } \\
(\mathrm{n}=186)\end{array}$ & $\begin{array}{c}\text { \% da raça no grupo } \\
\text { de raças definidas } \\
\text { (n=111) }\end{array}$ \\
\hline Boxer & 13 & 69,2 & 30,8 & 7,0 & 11,7 \\
Cocker Spaniel & 11 & 54,5 & 45,4 & 5,9 & 9,9 \\
Inglês & 07 & 28,6 & 71,4 & 3,8 & 6,3 \\
Teckel & 06 & 40,0 & 60,0 & 3,2 & 5,4 \\
Doberman & 06 & 40,0 & 60,0 & 3,2 & 5,4 \\
Dogue Alemão & 10 & 70,0 & 30,0 & 5,4 & 9,0 \\
Fila Brasileiro & 16 & 18,8 & 81,2 & 8,6 & 14,4 \\
Pastor Alemão & 15 & 46,7 & 53,3 & 8,1 & 24,3 \\
Rottweiler & 27 & 37,0 & 63,0 & 14,5 & 0,0 \\
Outras Raças & 75 & 38,7 & 61,3 & 40,3 & 100,0 \\
SRD & 186 & 41,4 & 58,6 & 100,0 & \\
\hline TOTAL & & & &
\end{tabular}

Tabela 2 - Distribuição das raças no total de cães atendidos no HV-UEL de outubro de 2002 a 2004, e ocorrência de linfoma canino neste período. Londrina - Paraná - Brasil, 2005

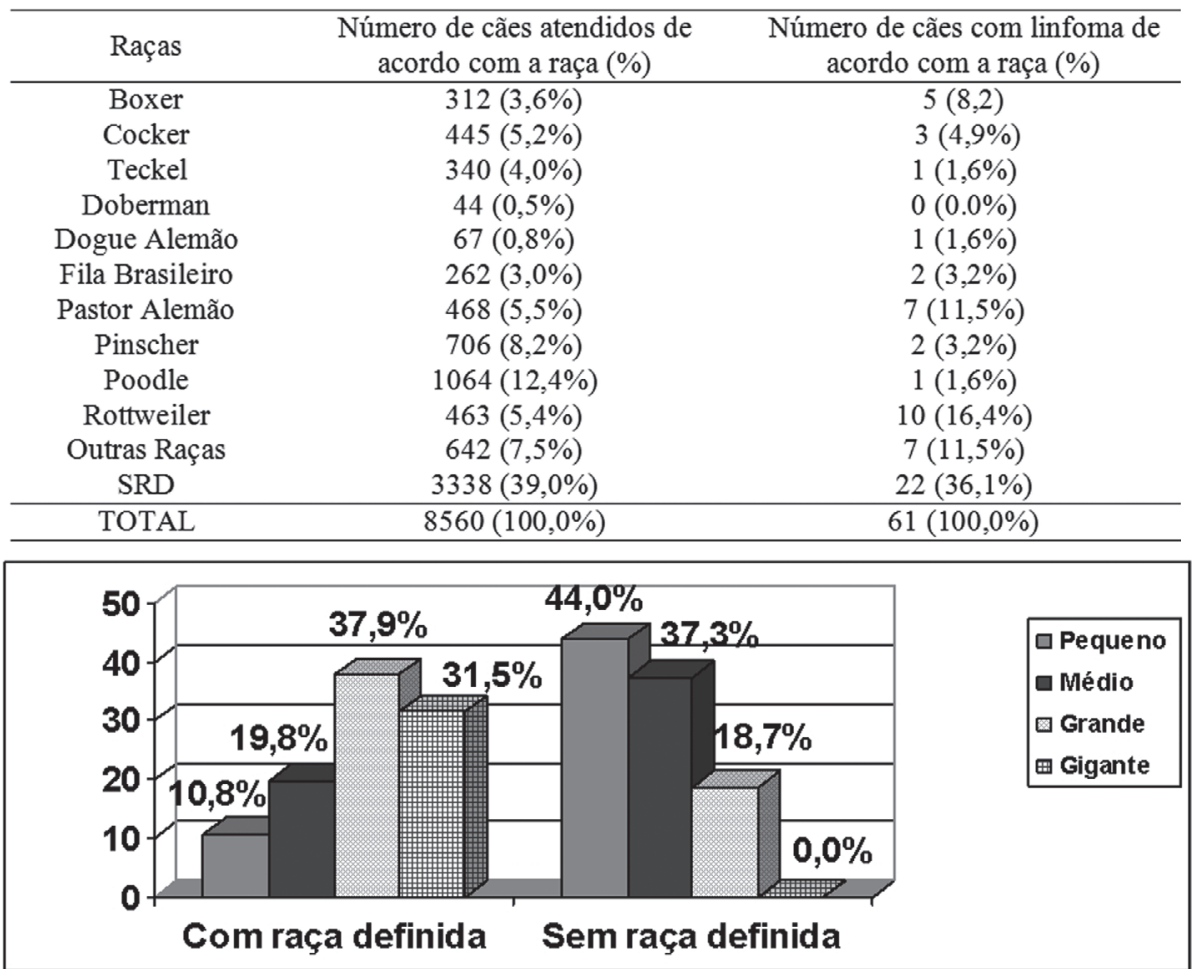

Figura 1 - Relação entre a ocorrência de linfoma (\%) em animais com e sem raça definida e o porte físico, em cães atendidos no HV-UEL, de janeiro de 1990 a outubro de 2004

\section{Discussão}

O linfoma canino é uma doença de apresentação clínica variável, o que dificulta um rápido diagnóstico. Conhecer dados epidemiológicos desta doença auxilia na obtenção de diagnóstico precoce e contribui para compreender o comportamento biológico da doença.

Predisposição racial já foi descrita em Scottish Terrier; Basset Hound; Airedale Terrier; Bulldog; Boxer; Golden Retrievier, 


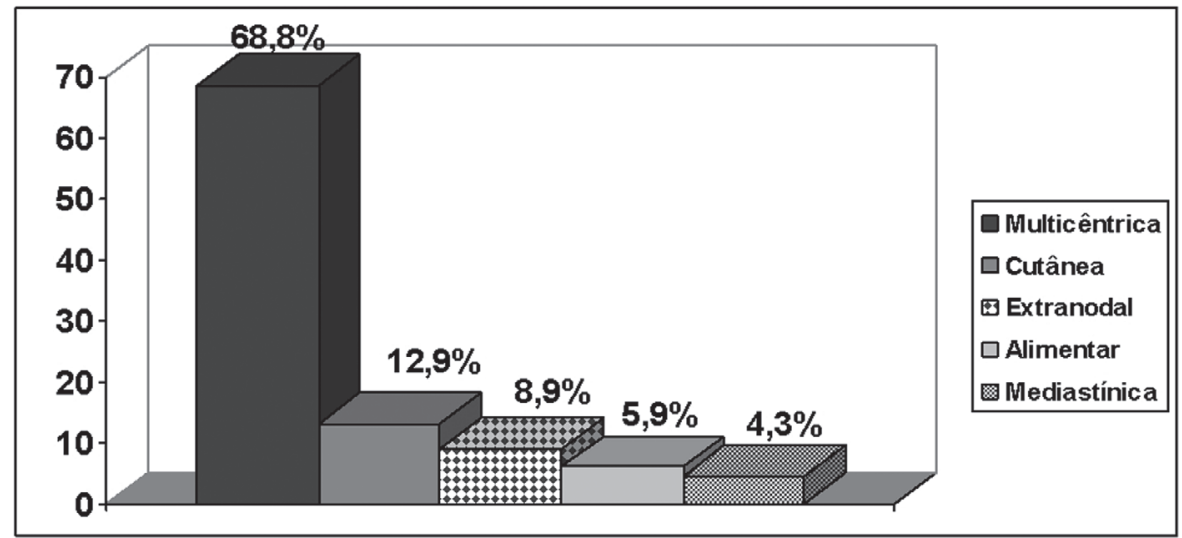

Figura 2 - Relação entre a ocorrência de linfoma (\%) e a classificação anatômica em cães atendidos no HV-UEL, de janeiro de 1990 a outubro de 2004

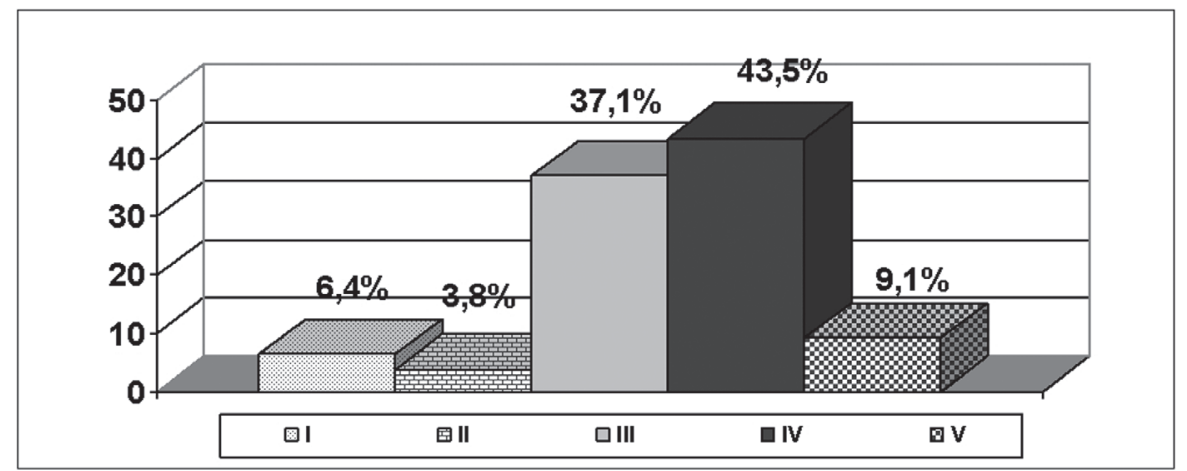

Figura 3 - Relação entre a ocorrência de linfoma (\%) e o estadiamento clínico, em cães atendidos no HV-UEL, de janeiro de 1990 a outubro de 2004

Poodle e Pastor Alemão 2, 8, 9 , enquanto a predisposição genética foi descrita em Bull Mastiff e Otterhounds ${ }^{6}$.

Neste estudo, podemos observar que cães de raça definida apresentaram uma maior ocorrência de linfoma do que cães SRD. No entanto, não foi observada predisposição racial na população estudada.

Ao constatarmos uma maior ocorrência em algumas raças, realizamos um segundo levantamento de todos os cães atendidos no HV-UEL no período de outubro de 2002 a outubro de 2004, para analisar a influência racial na ocorrência do linfoma em cães. Apesar de não haver significância na análise estatística quanto à predisposição racial, raças como o Pastor Alemão, Rottweiler e Boxer apresentam um grande número de animais atendidos e também um grande número com diagnóstico de linfoma. Ao contrário, raças como Poodle, Pinscher e Teckel, possuem uma grande população atendida no HVUEL, porém com baixo índice de diagnóstico de linfoma. Desta forma, há indícios de que cães das raças Pastor Alemão e Boxer atendidos no HV-UEL possam ter uma maior ocorrência de linfoma por predisposição racial, similar ao descrito na literatura.

Cães da raça Rottweiler não possuem predisposição racial de acordo com o descrito na literatura, porém é descrito predisposição genética em uma família de Rottweilers nos Estados Unidos. ${ }^{6}$ Neste estudo verificou-se uma ocorrência elevada nesta raça. Considerando que a maior parte dos cães Rottweiler no Brasil teve origem de cães importados, pode sugerir que subseqüentes cruzamentos e falta de controle na população de cães brasileiros, permitiram a difusão desta predisposição genética, encontrada em uma família de cães americanos, contribuindo com esta alta 
ocorrência detectada neste estudo.

Animais da raça Fila Brasileiro apresentaram ocorrência alta, porém não há descrição na literatura de que a raça tenha maior predisposição à doença, uma vez que a raça é pouco difundida pelo mundo. Outras raças descritas na literatura com alto risco relativo para o desenvolvimento do linfoma, não são comuns em nossa região.

No entanto, cães da raça Poodle que apresentam predisposição ao linfoma ${ }^{7}$ e que são comuns em nosso meio, não apresentaram ocorrência elevada. Considerando os dois últimos anos, foi diagnosticado um caso de linfoma em Poodle, o que equivale a 1,6\% dos cães com linfoma neste período. Porém, a população de Poodles no mesmo período, foi de $12,4 \%$ dos cães atendidos no HV-UEL. Desta forma, seria esperada maior ocorrência de linfoma em Poodle. Com isso, podemos inferir que não há uma clara predisposição para cães desta raça em nossa região. Novos estudos devem ser feitos nesta raça, para se determinar uma real predisposição para o linfoma.

Para as demais raças definidas, as ocorrências observadas em nosso estudo condizem com a predisposição racial descrita na literatura. Desta forma, podemos inferir que a predisposição racial descrita, também se aplica em nossos cães, mesmo existindo uma maior ocorrência em cães SRD.

Em cães de raça definida a maior ocorrência foi observada em animais de grande porte $(37,9 \%)$, assemelhando-se ao descrito na literatura nacional por De Moura e Sequeira ${ }^{13}$, Sequeira e Franco ${ }^{17}$, assim como a resultados descritos na literatura internacional ${ }^{7,18}$. Entretanto, em cães SRD constatou-se maior ocorrência de linfoma em cães de pequeno porte. Pode-se sugerir que o porte do animal aparentemente não tenha influência sobre a ocorrência da doença, tendo maior importância a predisposição racial.

A influência do sexo na ocorrência do linfoma canino é controversa, sendo descrita com maior freqüência em fêmeas por Teske? ${ }^{7}$ No entanto, em nosso estudo observou-se uma maior ocorrência em machos (58,6\%), assemelhando-se ao descrito por Rallis et al. ${ }^{9}$, assim como ao descrito em trabalhos realizados na região de Botucatu - São Paulo ${ }^{13,17,19}$. Apesar das divergências, acredita-se que não há influência do sexo na ocorrência do linfoma.

Valli ${ }^{20}$ relata a existência de indícios de menor ocorrência do linfoma em fêmeas e em machos castrados, o que permite inferir que pode haver influência de hormônios sexuais no aparecimento da doença.

Verifica-se que em algumas raças há maior ocorrência da doença em machos ou fêmeas. Animais SRD, Teckel, Doberman e Pastor Alemão apresentaram ocorrência em machos com variação de 70 a $81 \%$. No entanto, nas raças Boxer e Fila Brasileiro a ocorrência em fêmeas foi de 69,2 e $70 \%$, respectivamente. Nas demais raças, a ocorrência foi similar ao encontrado na população total de cães com linfoma. Mesmo verificando ocorrência mais acentuada em um dos sexos em determinadas raças, não é possível afirmar que há influência sexual quanto ao aparecimento da doença. No entanto, observa-se a necessidade de estudos epidemiológicos mais amplos, para se verificar a real possibilidade desta variável na ocorrência de linfoma em cães.

O linfoma canino é observado freqüentemente em animais adultos e idosos, com uma média de 6,3 a 7,7 anos. ${ }^{7,9}$ Moulton e Harvey ${ }^{5}$ descrevem uma freqüência de $80 \%$ dos casos em animais entre 05 e 11 anos. Resultados similares foram encontrados no Brasil por Sequeira e Franco ${ }^{17}$, que relataram uma freqüência de $80 \%$ dos casos em cães com idade entre quatro e treze anos.

Neste estudo, a idade média foi de 5,9 anos, similar a descrita por Teske ${ }^{7}$, sendo a faixa etária de dois a cinco anos de idade, com 45,1\%. Estes resultados assemelhamse aos descritos por De Moura e Sequeira ${ }^{13}$, na região de Botucatu - São Paulo.

Quanto à classificação anatômica do linfoma, A forma multicêntrica, caracterizada por linfoadenomegalia generalizada, é a mais 
comum em cães. Madwell e Theilen ${ }^{21}$ estudaram 144 casos e verificaram que $84 \%$ dos casos eram multicêntricos, $6,9 \%$ alimentar, 5,0\% mediastínicos, sendo a forma cutânea e extranodal as de menor freqüência. Estudo realizado por Sequeira et al. ${ }^{19} \mathrm{em}$ Botucatu demonstrou um percentual de $91,2 \%$ da forma multicêntrica, 5,9\% mediastínica e 2,9\% alimentar. Neste estudo, a forma multicêntrica foi a mais comum $(68,8 \%)$, entretanto diferiu da literatura quando se analisa o percentual das outras apresentações anatômicas.

O linfoma alimentar e mediastínico determinam sinais inespecíficos no paciente, dificultando um correto diagnóstico da doença. Tendo em vista que estas apresentações normalmente possuem um pior prognóstico, muitos animais vêm a óbito sem o diagnóstico correto. Além deste fator, nem todos os animais que vêm a óbito são submetidos à necropsia, podendo determinar uma menor ocorrência destas apresentações anatômicas do linfoma em cães.

Outro aspecto a ser considerado, é o fato de o linfoma multicêntrico poder infiltrar em qualquer parte do organismo, mimetizando algumas vezes outra forma anatômica. Além destes aspectos, considerase que diferenças ambientais e o tipo de alimento podem interferir na apresentação. ${ }^{22}$

Em relação ao estadiamento clínico descrito pela Organização Mundial de Saúde (OMS), que estabelece os órgãos infiltrados com a doença e a presença ou ausência de sinais clínicos, a maior ocorrência foi observada nos estádios IV e III, com 43,6\% e 37,1\% respectivamente. Estes achados concordam com os descritos na literatura, que refere uma maior facilidade em diagnosticar os estádios avançados já que são mais facilmente percebidos pelos proprietários. ${ }^{7,23}$ Os estádios III e IV apresentam resultados similares em muitos estudos. Porém, para avaliação do estádio $\mathrm{V}$ deve-se realizar obrigatoriamente a punção de medula óssea. Neste caso, muitos trabalhos podem não ter uma maior prevalência do estádio $V$, pela ausência de análise da medula óssea. Neste trabalho, em 30 animais foram realizadas as punções da medula óssea para análise. Em 45\% destes foi detectada a presença de infiltrado linfóide neoplásico, caracterizando assim o grau $\mathrm{V}$ do linfoma. Apenas 03 destes animais possuíam alterações hematológicas, sendo que dois apresentavam anemia normocítica normocrômica e apenas um estava com linfocitose. Desta forma, possivelmente o estádio $\mathrm{V}$ esteja sub-representado devendose fazer um estudo prospectivo para se avaliar a real prevalência do estádio nos cães com linfoma.

Com isto, vale ressaltar que alguns dados deste estudo assemelham-se aos descritos na literatura consultada. No entanto, devemos considerar a necessidade de estudos mais amplos para se verificar possíveis fatores que determinam uma menor ocorrência da doença na raça Poodle em nossa região, uma vez que esta raça é muito comum em nosso meio e considerada pela literatura como de maior risco relativo para o aparecimento da doença. Ao mesmo tempo, também há necessidade de verificar possíveis fatores que determinam uma alta ocorrência da doença em cães Rottweiler e Fila Brasileiro, a real influência sexual em determinadas raças e a importância do porte físico como indicativo de maior ou menor risco para o aparecimento da doença.

\section{Retrospective study of canine lymphoma in period 1990 - 2004, north region the of Paraná}

\section{Abstract}

Canine malignant lymphoma (CML) is a common lymphoid tumor. Canine lymphomas from 1990 to 2004 ( $n=186)$ were analyzed on epidemiological aspects. The occurrence of CML in males (58,6\%) was greater than in females $(41,4 \%)$. The middle age of affected dogs
Key words:

Canine malignant lymphoma.

Epidemiological aspects.

Lymphoma anatomical classification. Lymphoma clinical staging. 
was 5,9 years. The most common breeds in this study were mixed breed (40,3\%), German Sheepdog (8,6\%), Rottweiler (8,1\%) and Boxer $(7,0 \%)$. For the anatomical classification and the clinical staging of CML, the most common were multicentric form $(68,8 \%)$ and stage III $(37,1 \%)$ and IV (43,5\%), respectively.

\section{Referências}

1 MILNER, R. J. et al. Immunophenotypic classification of canine malignant lymphoma on formalin-fixed paraffin wax-embedded tissue by means of CD2 and CD79a cell markers. Onderspoort Journal of Veterinary Research, v. 63, p. 309-313, 1996.

2 DOBSON, J. M. et al. Prognostic variables in canine multicentric lymphosarcoma Journal of Small Animal Practice, v. 42, p. 377-384, 2001

3 FOURNELL-FLEURY, C. et al. Cytohistological and immunological classification of canine malignant lymphomas: comparison with human non-Hodgkin's lymphomas. Journal Comparative Pathology, v. 117, p. 35-59, 1997.

4 FOURNELL-FLEURY, C. et al. Canine T-cell lymphomas: a morphological, immunological, and clinical study of 46 new cases. Veterinary Pathology, v. 39, p. 92-109, 2002.

5 MOULTON, J. E; HARVEY, J. W. Tumors of the lymphoid and hematopoietic tissues In: MOULTON, J.E. Tumors in domestic animals. London: University of California Press, 1990. p. 231-244.

6 VAIL, D. M.; MacEWEN, E. G.; YOUNG, K. M. Canine lymphoma and lymphoid leukemias. In: WITHROW, S. J.; MacEWEN E. G. Small animal clinical oncology. 3.ed Philadelphia: W.B. Saunders, 2001. p. 558-590.

7 TESKE, E. Canine malignant lymphoma: a review and comparison with human non-Hodgkin's lymphoma. Veterinary Quarterly, v. 16, n. 4, p. 209-219, 1994.

8 MELLANBY, R. J.; HERRTAGE, M. E.; DOBSON, R. J. Treatment of canine lymphoma by veterinarians in first opinion pratice in England. Journal of Small Animal Practice, v. 43, p. 198-202, 2002.

9 RALLIS, T. et al. Lymphoma (malignant lymphoma, lymphosarcoma), in the dog. Journal of Small Animall Practice, v. 33, p. 590-596, 1992.

10 CROW, S. E. Lymphosarcoma (malignant lymphoma) in the dog: diagnosis and treatment. The Compendium on Continuing Education, v. 4, n. 4, p. 283-292, 1982.

11 OWEN, L. TNM Classification of tumors in domestic animals. Geneva. World Health Organization, 1980. p. 46-47.

$12 \mathrm{DAY}, \mathrm{M} . \mathrm{J}$. Immunophenotypic characterization of cutaneous lymphoid neoplasia in the dog and cat. Journal Comparative Pathology, v. 112, p. 79-96, 1995.

13 De MOURA, V. M. B. D.; SEQUEIRA, J. L. Linfoma canino. Revista de Educação Continuada do CRMV SP, v. 2, n. 2, p. 29-33, 1999.

14 THRALL, M. et al. Cutaneous lymphosarcoma and leukemia in a dog resembling Sézary syndrome in man. Veterinary Pathology, v. 21, p. 182-186, 1984.

15 TESKE, E. et al. Prognostic factors for treatment of malignant lymphoma in dogs. Journal Americam Veterinary Medical Association, v. 205, n. 12, p. 1722 1728, 1994

16 TESKE, E.; Van HEERDE, P.; Diagnostic value and reproducibility of fine-needle aspiration cytology in canine malignant lymphoma. Veterinary Quarterly, $v$. 18, n. 3, p. 112-115, 1996.

17 SEQUEIRA, J. L.; FRANCO, M. Características anátomo-clínicas dos linfomas caninos. Jornal de Anatomopatologista, v. 7. n. 2, p. 6-8, 1992.

18 KIUPEL, M.; TESKE, E.; BOSTOCK, D. Prognostic factors for treated canine malignant lymphoma. Veterinary Pathology, v. 36, p. 292-300, 1999.

19 SEQUEIRA, J. L. et al. Características Anatomoclínicas dos Linfomas Caninos na região de Botucatu/SP. Arquivo Brasileiro de Medicina Veterinária e Zootecnia, v. 51, n. 3, p. 245-249, 1999.

20 VALLI, V. E. O. The hematopoietic system. In: JUBB, K. V. F.; KENNEDY, P. C., PALMER, N. Pathology of domestic animals. 4 ed. New York: Academic, 1993. v. 3 , p. $149-153$.

21 MADWELL, B. R.; THEILEN, G.H. Hematopoietic neoplasms, sarcomas and related conditions. Part IV: Canine. In: THEILEN, G. H.; MADWELL, B. R. (Ed.) Veterinary cancer medicine. 2ed. Philadelphia: Lea Febiger, 1987. p. 392-407.

22 VONDERHAAR, M. A.; MORRISSON, W. B. Lhymphosarcoma. In: MORRISON. W.B. Cancer in dogs and cats. Philadelphia: Willians \& Wilkins, 1998, p. 667-695.

23 GREENLEE, P. G. et al. Lymphoma in dogs. A morphologic, immunologic and clinical study. Cancer, v. 66, p. $480-490,1990$.

24 DeBOER, D. J.; TURREL, J. M.; MOORE, P. F. Mycosis fungoides in a dog: demonstration of T-cell specificity and response to radiotherapy Journal of the Americam Animal Hospital Association, v. 26, p. 566572, 1990.

25 FRENCH, R. A; SEITZ, S; E; VALLI, E. O Primary epitheliotropic alimentary T-cell lymphoma with hepatic involvement in a dog. Veterinary Pathology, v. 33, p. 349-352, 1996. 